\title{
O POTENCIAL DO PATRIMÔNIO PRESERVADO ENTRE PORTO DE PEDRAS E PORTO CALVO
}

\author{
Marcos Albuquerque
}

Doris Walmsley de Lucena

\begin{abstract}
Veleda Lucena
Resumo: O Manguaba é um rio de águas mansas que serpenteia nas terras baixas do norte alagoano. Esta rede de caminhos foi particularmente útil durante os combates travados quando da invasão holandesa do Brasil, no século XVII. A iconografia holandesa nos mostra o quanto se empenharam em conhecer os caminhos que conectavam os assentamentos lusobrasileiros. Ali se pode observar o registro de pontos de moradias, engenhos, capelas e os caminhos que os conectavam. Alguns destes assentamentos tiveram continuidade ao longo da história, outros se perderam na memória, desapareceram do cotidiano da população. Mas seu registro arqueológico é possível de ser resgatado. Assim se buscou, através da prospecção arqueológica recuperar os locais apontados pela cartografia holandesa, sobretudo no mapa BQPPB de George Marcgraf. Palavras-Chave: Patrimônio da guerra holandesa; Holandeses no Brasil; Arqueologia Histórica
\end{abstract}

Abstract: The Manguaba is a river of calm waters that meanders in the Lowlands of northern Alagoas. This network of paths was particularly useful during the combats that took place in the Dutch invasion of Brazil, in the seventeenth century. The Dutch iconography show us how much they worked to know the roads that connected the Luso-Brazilians settlement. Such elements are the confirmation of the effort made to settle in the land and provide their sustenance and plus to build a new nation. Some of these settlements have continued throughout history, others have lost in memory, disapeared from the daily lives of population. But its archaeological register is possible to be rescued. Thus, through archaeological prospection, the aim was to recover the registered sites in the Dutch cartography, especially in the BQPPB map of Georg Maggraf. Keywords: Dutch war patrimony; Dutch in Brazil; Historical Archaeology

Coord. do Laboratório de Arqueologia UFPE.

iiPesquisadora autônoma

iii'Arqueóloga da Arqueolog
Pesquisa 
Introdução

Quando em 2008/09 foi realizado o Levantamento Histórico Arqueológico da zona urbana de Porto de Pedras/AL, um projeto de pesquisa de iniciativa da Superintendência Regional do IPHAN/Alagoas, ficou evidente o potencial arqueológico disponível em Porto de Pedras e seus arredores. Potencial praticamente desconhecido, sobretudo do ponto de vista material. Potencial que não remete apenas a história local e a episódios esporádicos, mas sim a história nacional e ainda à herança comum entre vários países, dos quais se destaca Portugal, Brasil, Espanha e Holanda. O estudo arqueológico desta região, imiscuído com um programa de educação patrimonial, muito contribuirá para a consolidação da cidadania, permitindo um maior entendimento desta sociedade que teve praticamente toda a linha do tempo preenchida com fatos e episódios relacionados com a História Nacional, desde a sua préhistória até os dias atuais. Naquela ocasião os pesquisadores envolvidos, cientes dos riscos a que estão submetidos os sítios arqueológicos, da faixa litorânea e adjacências, mormente os ainda não identificados, manifestaram sua

\footnotetext{
esperança de que um Programa de Pesquisa Arqueológica venha a ocorrer antes de um novo combate, o da especulação imobiliária desenfreada que ocorre especialmente no nordeste cálido deste País. Programa que não apenas resgate informações curiosas, mas que sobretudo contribua para a autoestima de seu povo, pois uma sociedade que não conhece seu passado não tem perspectiva de futuro. (Albuquerque, 2014)
}

Aquele Projeto de Prospecção Arqueológica, em sua etapa de campo, concentrou suas buscas na bacia do rio Manguaba, mormente no trecho navegável do rio, entre a cidade de Porto Calvo e sua foz no Município de Porto de Pedras, no Estado de Alagoas. Saliente-se ainda um estudo realizado pelo NEPA/UFAL, sob coordenação do Prof. Dr. Scott Allen, financiado pelo IPHAN/AL, e que teve como foco principal a identificação dos antigos engenhos de açúcar. A pesquisa Rota da Escravidão/Rota da Liberdade: etapa 1, que identificou alguns sítios arqueológicos e locais de interesse arqueológico nos municípios de Porto Calvo e Porto de Pedras, segundo informação do Iphan/AL. Este novo Programa, ainda de iniciativa da Superintendência Regional do Iphan/Alagoas, buscou, com base nos resultados anteriormente alcançados, concentrar esforços no entorno do Rio Manguaba que estabelece a conexão entre os dois polos de maior projeção naquele trecho do litoral de Alagoas: Porto de Pedras e Porto Calvo. 
Como grande parte dos rios do Nordeste, que correm no sentido oeste/leste, o rio Manguaba é de pequeno curso. Em seu baixo curso, um rio de águas mansas, meandrante, atravessando as terras baixas formadas pelos recortes da erosão dos tabuleiros costeiros. Sofrendo a influência das marés, parte de seu curso reflete na salinidade de suas águas o quanto as águas do mar chegam a ocupar seu leito ${ }^{1}$. O mesmo reflexo é marcado pela vegetação instalada em suas margens. O manguezal acompanha as margens do Manguaba por vários quilômetros, permitindo que a fauna estuarina permeie as terras mais afastadas do litoral através dos riachos que drenam os terraços e deságuam no Manguaba. Na área estuarina o Manguaba contribui com seus sedimentos para a engorda das praias mais ao norte, como é o caso da ponta de Japaratinga. Mas é nos recortes que faz no terreno, com seu curso sinuoso que o Manguaba forma um grande largo, ao abrigo das ondas. A despeito do assoreamento atual o remanso que ali se forma é certamente uma área segura para fundear embarcações. De resto, a área de Porto de Pedras ou Porto das Pedras, como é referida na documentação histórica, constitui um porto abrigado, com pelo menos duas barras maiores e outras de menor amplitude. Barras que permitiram o intenso movimento de barcaças e navios que vinham para carregar com o açúcar produzido nos engenhos da Alagoas Borealis.

Para Porto Calvo, um povoado, depois vila, convergia grande parte do açúcar produzido na região. Convergência que se reflete nos numerosos caminhos já registrados na iconografia holandesa da primeira metade do século XVII.

Considerando a densidade de informações históricas, textuais e iconográficas que convergem ao período de conquista e dominação holandesa no Brasil, envolvendo a área do Rio Manguaba, optou-se por enfocar a busca pelo patrimônio eventualmente ali preservado, naquele período. Deste modo, a pesquisa arqueológica sobre a área buscou estabelecer inicialmente um panorama geral, para posteriormente enfocar o levantamento sistemático, por unidade arqueológica estabelecida. O critério estabelecido para a definição das unidades arqueológicas levou em consideração as referências históricas relacionadas ao período enfocado, entretanto eventuais sítios arqueológicos de outros períodos não seriam ignorados.

Dentre a documentação histórica que serviu de base mereceu particular destaque a cartografia coeva. Assim mostrou-se particularmente útil nesta etapa de trabalho os mapas

\footnotetext{
${ }^{1}$ A salinidade das águas do Manguaba, medida no Varadouro, em Porto Calvo, na época da estiagem, apresentou uma baixa salinidade, compatível com água potável.
} 
elaborados por cartógrafos holandeses, bem como as ilustrações, sejam as iluminuras sejam os desenhos ou quadros holandeses que retratam aquela área específica. Este tipo de abordagem foi anteriormente utilizado pela equipe, em trabalho realizado em Penedo (Alagoas) em 2005, quando os trabalhos de Marcgraf e de Frans Post, por exemplo, foram particularmente úteis.

No presente estudo tomou-se por base o mapa mural Brasilia Qua Parte Paret Belgis ${ }^{2}$, de autoria de Georg Marcgrave ${ }^{3}$, os mapas das Capitanias ${ }^{4}$, originalmente publicados no livro de Barléus ${ }^{5}$ :

- PRAFECTURA DE CIRÎl I vel SEREGIPE DEL REY cum Itâpuáma

- PRAEFECTURAE PARANAMBUCAE PARS MERIDIONALIS'

O mapa de Marcgrave de 1643 é conhecido "sob duas formas, a partir de quatro gravuras individuais que consistem nos mapas propriamente ditos, utilizados por Gaspar Barléus, representando as capitanias conquistadas; e como mapa mural, editado por Joan Blaeu, em 1647, confeccionado a partir da sobreposição e colagem de onzes folhas e do acréscimo de textos em francês, latim e holandês, e que recebe o título de 'Brasilia qua parte paret Belgis'”6 (Menezes, 2011:08). Trata se de uma obra de grandes dimensões (101 cm x $160 \mathrm{~cm}$ ), que abrange desde a Capitania de Sergipe, até o Rio Grande (do Norte), detendo se em detalhes sobre os rios e outros acidentes geográficos, caminhos, engenhos e povoados.

Complementando esse trabalho, também se dispôs de informações oriundas dos seguintes mapas, que mostram as posições das tropas de Nassau e das fortificações, etc., durante o cerco em 1637:

- Planta PORTUS CALVUS (Barleus, 1647)

- VISTA DO CERCO E CONQUISTA DE PORTO CALVO, detalhe do folheto Auctentijck Verhael van de Belegheringhe ende veroveringhe van Porto Calvo [Descrição autêntica do Cerco e Conquista de Porto Calvo], desenho atribuído ao Coronel Cristofel Arciszewsky e impresso por lan van Hilten, Amsterdam, 27/6/1637 (acervo do Nederlands Scheepvaartmuseum, Amsterdam).

2 Marggraphius, 1660.

3 Nesse trabalho, vários dos topônimos, além da sua localização gráfica aproximada a simbologia utilizada pelo autor do original traz informações correlatas do tipo "engenho d'água, moente",

4 Blaeu, 1665.

5 Barléu, 1647

6 Menezes, 2011. 
O levantamento cartográfico conduziu ainda ao projeto Brasilia Qua Parte Paret Belgis, do professor Levy Pereira, disponível em: http://Ihs.unb.br/wiki_files/HISTORIA.exe ${ }^{7}$, que traz comentários descrevendo sua natureza, nomes históricos, o nome atual, e citações nas fontes primárias e secundárias, tanto iconográficas como bibliográficas (Figura 1).

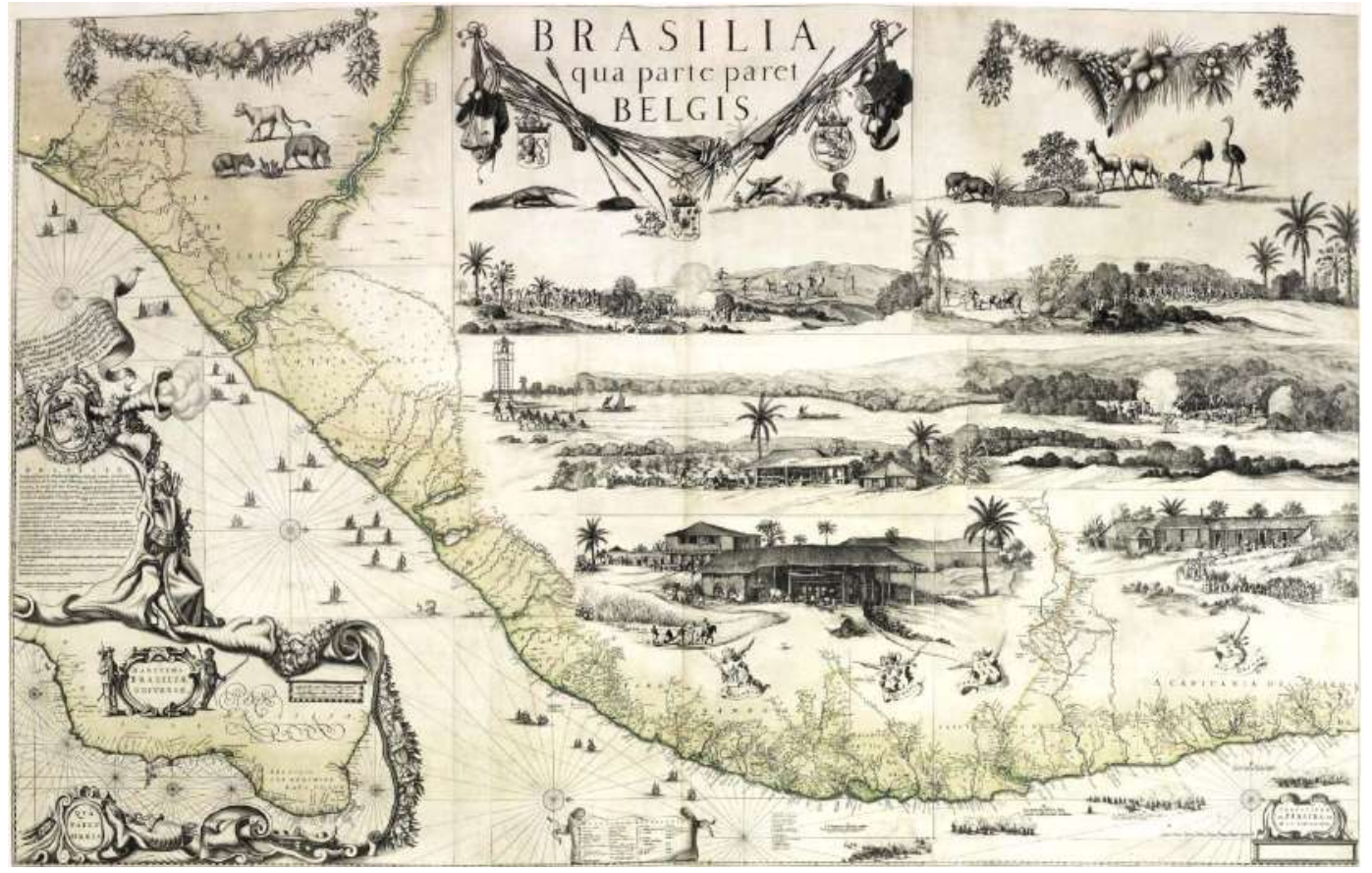

Figura 1: Mapa Mural Brasilia Qua Part Paret Belgis, de George Marcgraf - Mapa\#38, Klenke Atlas British Library.

Assim, com base nos dados históricos e, considerando os pontos notáveis assinalados na cartografia, buscou-se localizar no terreno aqueles pontos, de modo a identificar os locais de maior potencial arqueológico.

Buscou se inicialmente, a partir dos rios e riachos assinalados, identificar as estradas e trilhas, que pudessem ser associadas àquelas registradas pela cartografia (Figura 2).

Muitas delas praticamente abandonadas, restringiam se hoje a pequenos trechos, acessos a propriedades particulares. Outras continuaram em uso, sendo hoje vias principais de acesso como é o caso da rodovia AL 460 no trecho que liga Porto de Pedras a Porto Calvo, pela margem direita do Manguaba. 


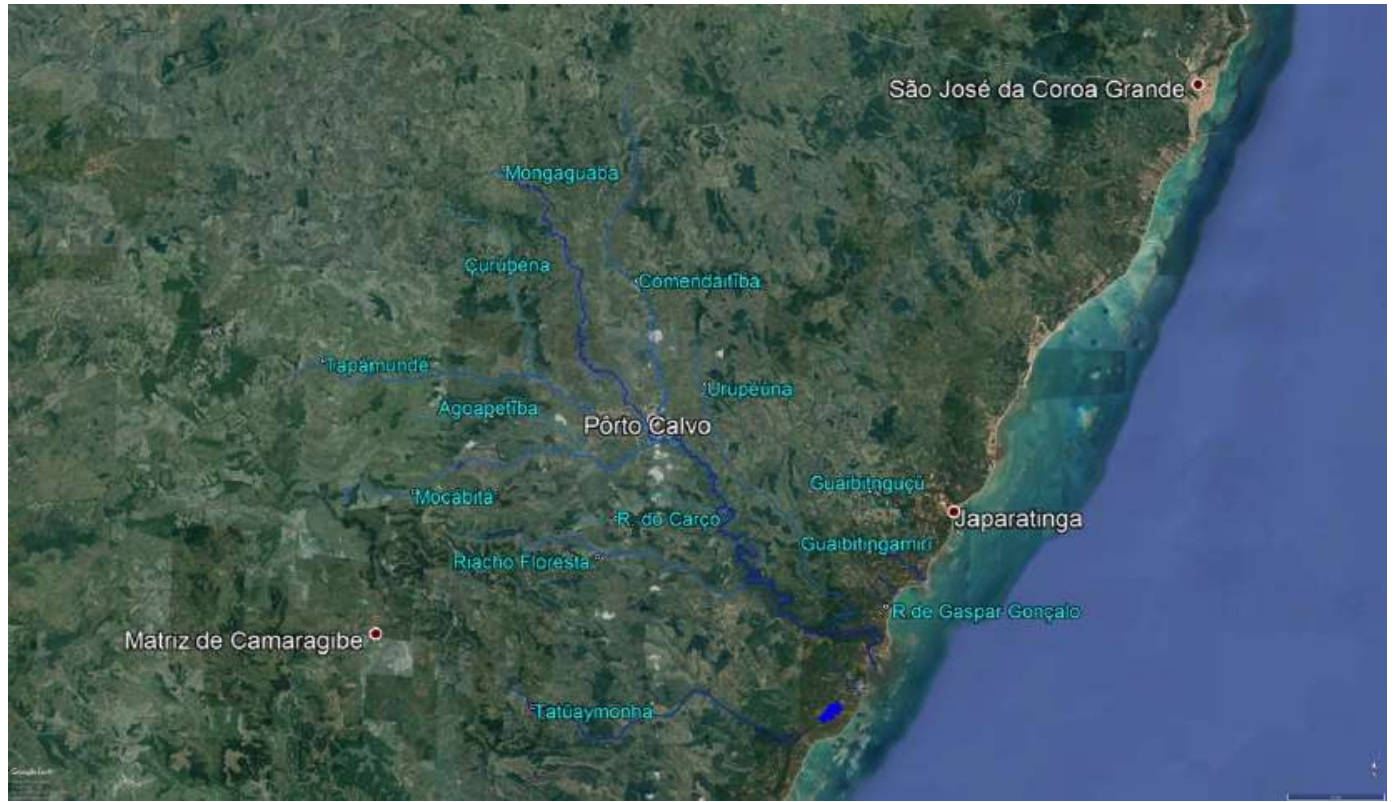

Figura 2: Principais afluentes do Manguaba e outros rios referidos na cartografia, identificados e georeferênciados pelo Projeto

A identificação dos cursos d'água e dos caminhos, propiciou elementos de checagem com os pontos notáveis assinalados na cartografia, para sua reconstituição em campo (Figura 3).

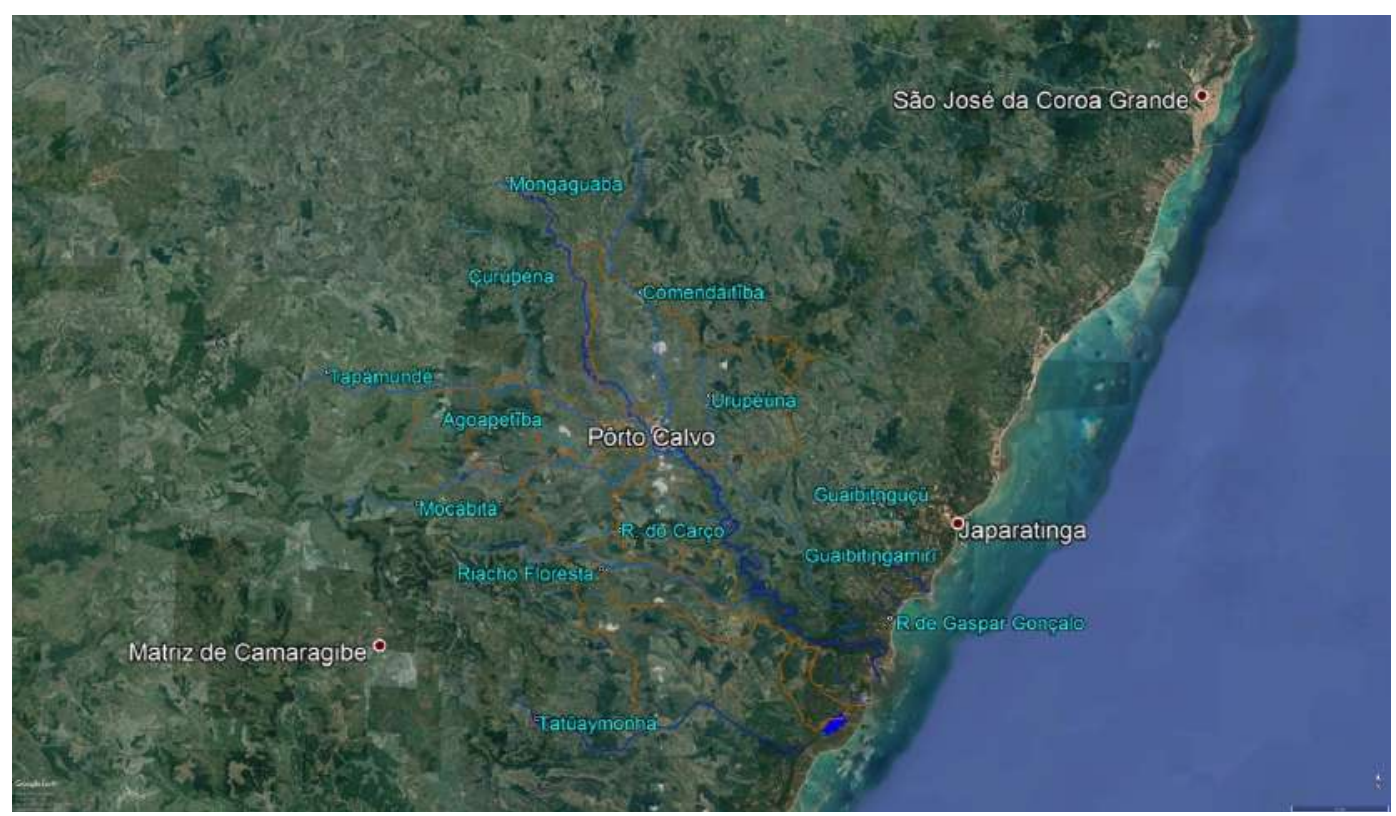

Figura 3: Caminhos registrados na cartografia (grafados em laranja), em sua maioria estabelecem comunicação entre dois rios. Os caminhos ou suas marcas, foram identificados em campo e georreferenciados.

Como a casa situada entre o 'Monguagaba' (Rio Manguaba) e o 'Urupéûna' (Rio Grupiuna) referida na iconografia como Wittehuys. 
O local marcado como Wittehuys no mapa encontra- se atualmente dentro da Fazenda Crasto - Propriedade de Celso Luiz Palatti Neto, e fica ao lado direito da atual casa da sede da fazenda que foi construída em 1963. Assim como a Wittehuys, outras, cujo nome ou proprietário não é mencionado, mas estão assinaladas no mapa, suas localizações foram identificadas e georreferenciadas, como aquela que hoje estaria no Povoado Canavieira, ou outra na margem direita do rio Carço, e ainda aquelas cuja localização aponta para o atual Povoado Bitingui (hoje município de Japaratinga), e mesmo aquelas próximas ao mar (zona urbana de Porto de Pedras e zona urbana do povoado de Curtume).Ainda no interior as casas assinaladas em terras onde hoje é a Fazenda Água de Prata e na Fazenda Bateria, na encosta de um morro, no lado esquerdo da AL460 (Figura 4).

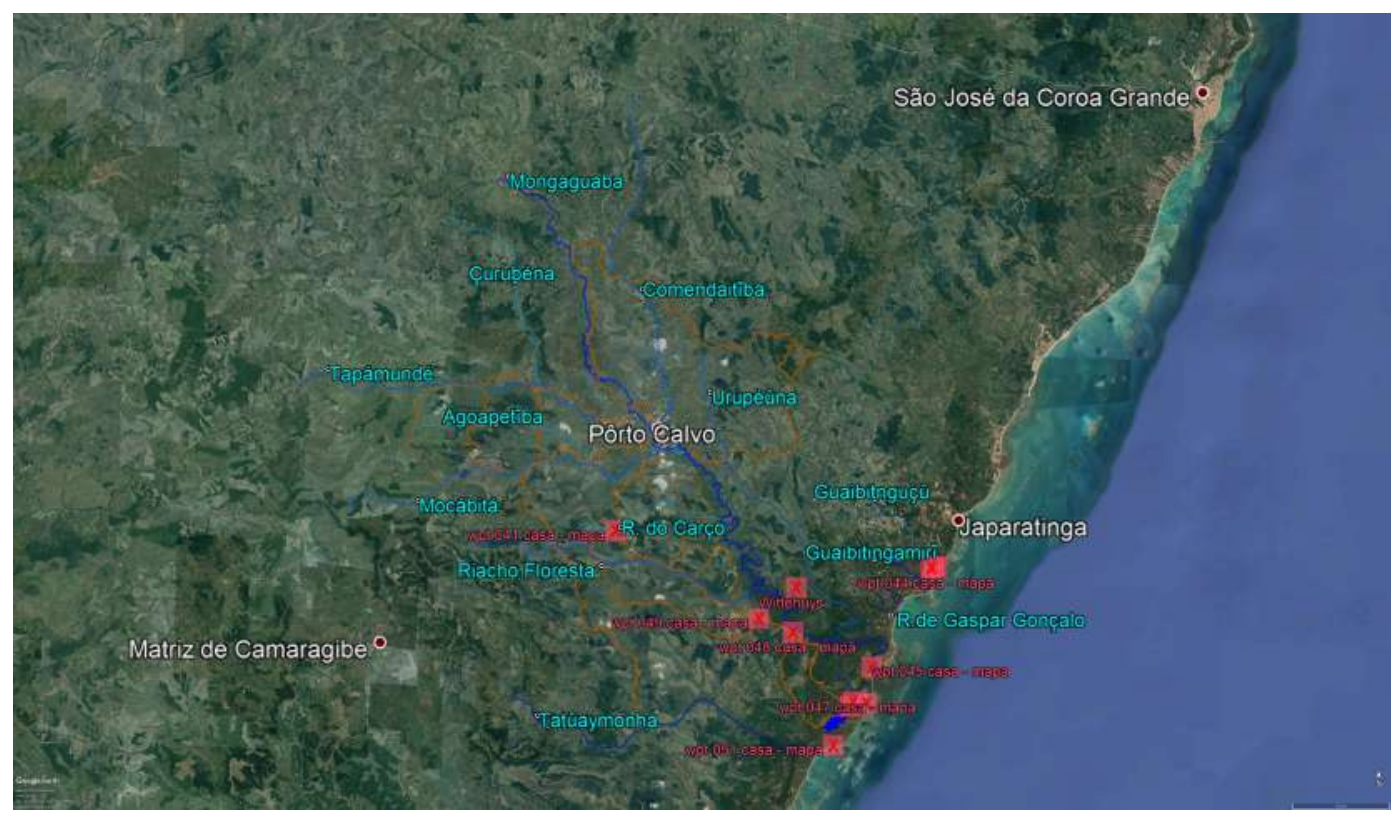

Figura 4: Conjunto das casas assinaladas nos mapas holandeses, cuja localização foi identificada em campo e georreferenciado em mapa.

Foram ainda georreferenciados os engenhos assinalados na cartografia, assim como as igrejas referidas na cartografia holandesa ou mencionadas em textos, assim como povoados como o de Quitanga e Caxangá, além das fortificações e locais de batalha (Figura 5).

Ao longo do Manguaba, entre Porto de Pedras de Porto Calvo, foram identificados e georreferenciados os portos mencionados na documentação, e que ainda são conhecidos e utilizados nos dias atuais, assim como o chamado Lagamar da Ratéia (Figura 6). 


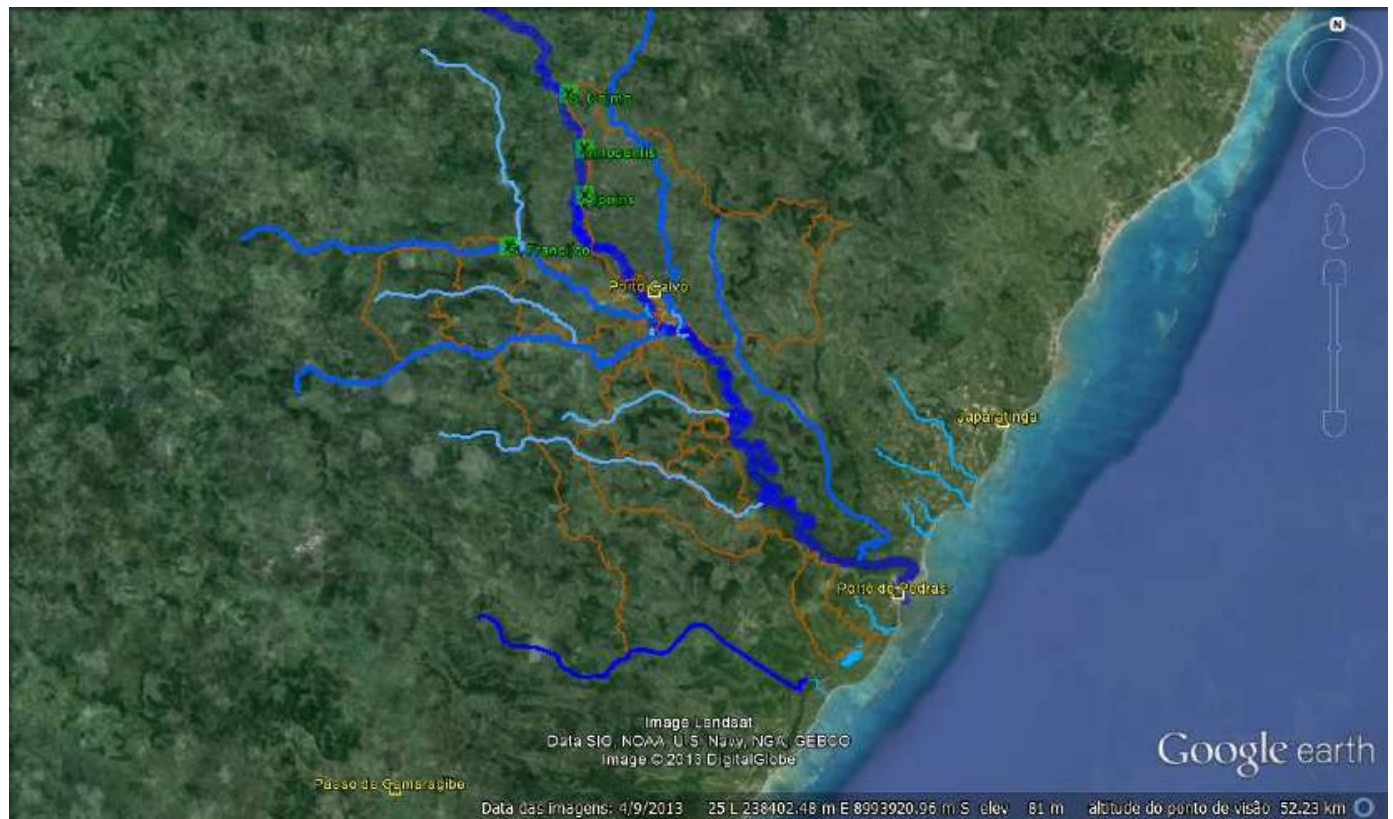

Figura 5: Conjunto dos engenhos assinaladas nos mapas holandeses; o local assinalado foi identificado em campo e georreferenciado.

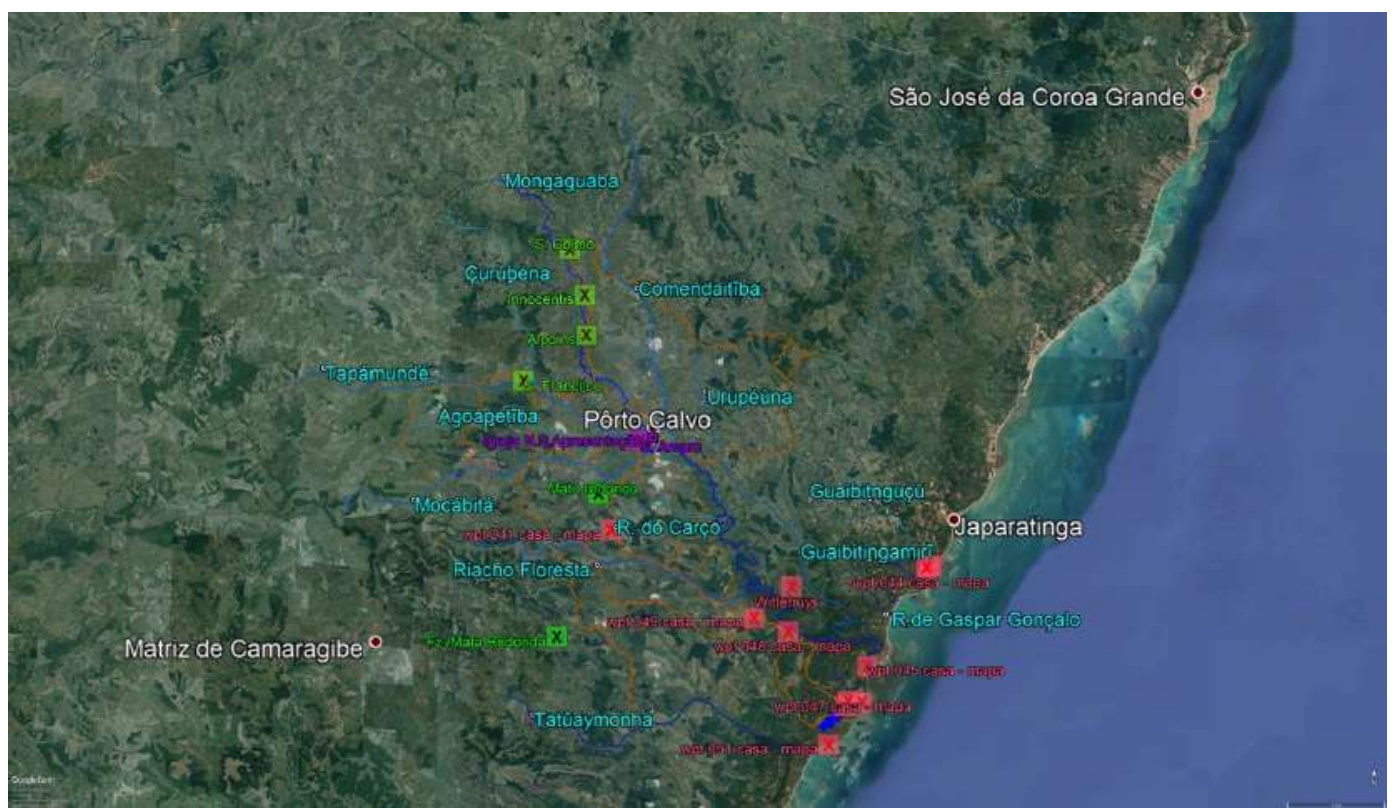

Figura 6: Conjunto dos assentamentos que constam no BQPPB (no trecho considerado) que foram identificados em campo e georreferenciados.

Os trabalhos em campo consideraram não apenas a cartografia e as referências textuais, mas tomaram por base ainda a iconografia disponível em desenhos, que buscava retratar os locais e a distribuição das tropas no entorno de Porto Calvo, os campos de batalha, e a distribuição das estruturas de defesa. Neste tocante, além dos desenhos de Frans Post, foi de suma importância o plano ou relatório do cerco de Porto Calvo, elaborado pelo coronel Arciszewsky. 
Desde 1634 implantara-se na Vila de Porto Calvo um sistema de defesa que teve início com a fortificação de sua antiga igreja (igreja velha) (Figura 7).

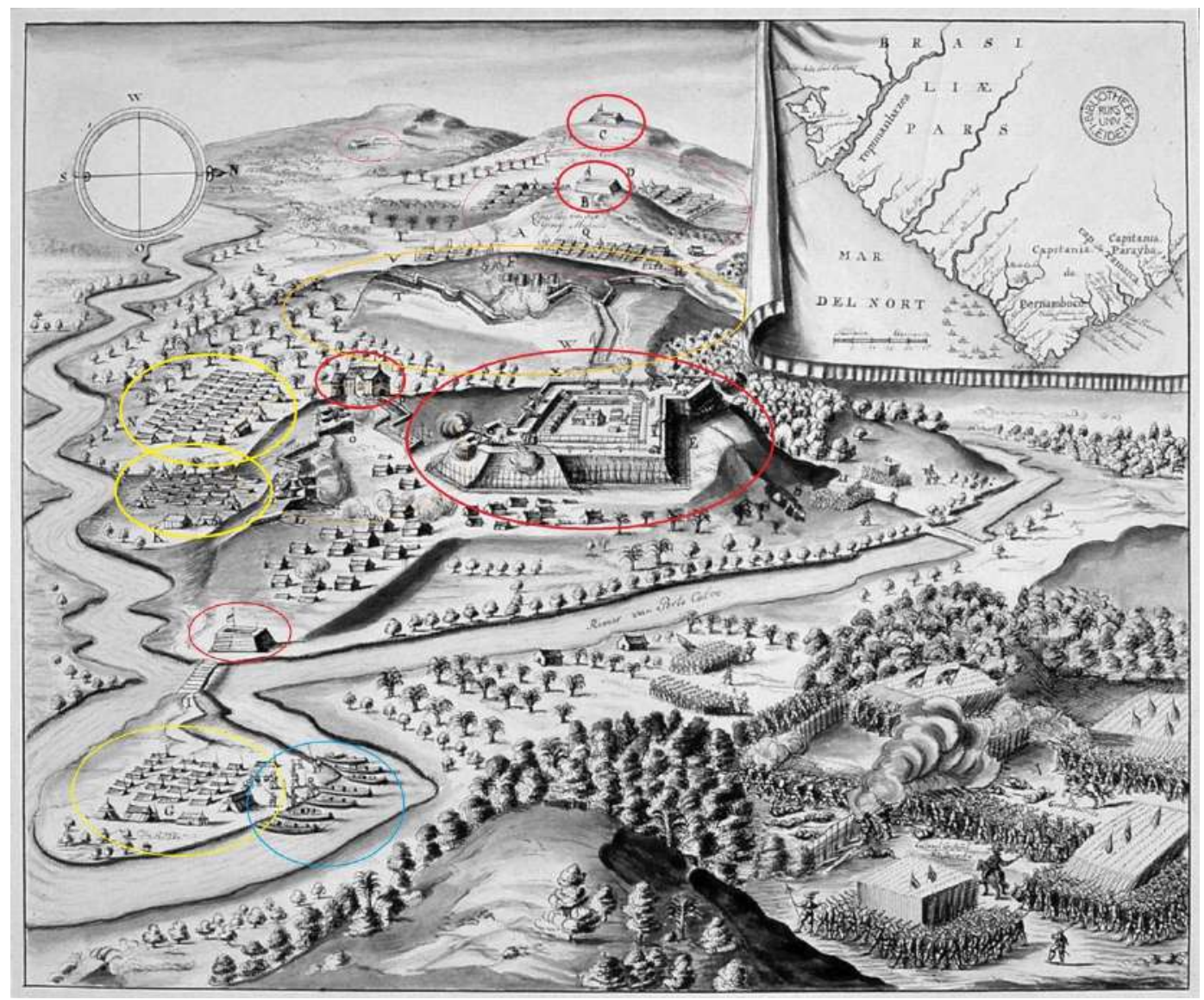

Figura 7: Cerco de Porto Calvo. Originalmente foi feito pelo coronel Crestofle d'Artischau Arciszewsky (assinalados os pontos de interesse). Mapa da coleção Bodel Nijenhuis da Biblioteca Universitária, Leiden (Ublcka_Coubn 002-12-076

Aquela igreja foi posteriormente demolida dando lugar às obras da fortaleza. Uma nova igreja foi construída, e posteriormente também fortificada.

Há referências ainda a duas 'casas fortes' no povoado que se estendia entre os dois fortes. No varadouro, dois redutos integravam ainda a defesa da Vila. Um pouco mais afastados, nos outeiros de Amador Álvares outros dois redutos se erguiam a cavaleiro da estrada que vinha do Norte.

O estudo realizado permitiu localizar-se grande parte dos pontos de defesa mencionados nas fontes utilizadas. Alguns foram drasticamente sobrepostos com obras modernas, mormente aqueles da área urbana (Figura 8). 


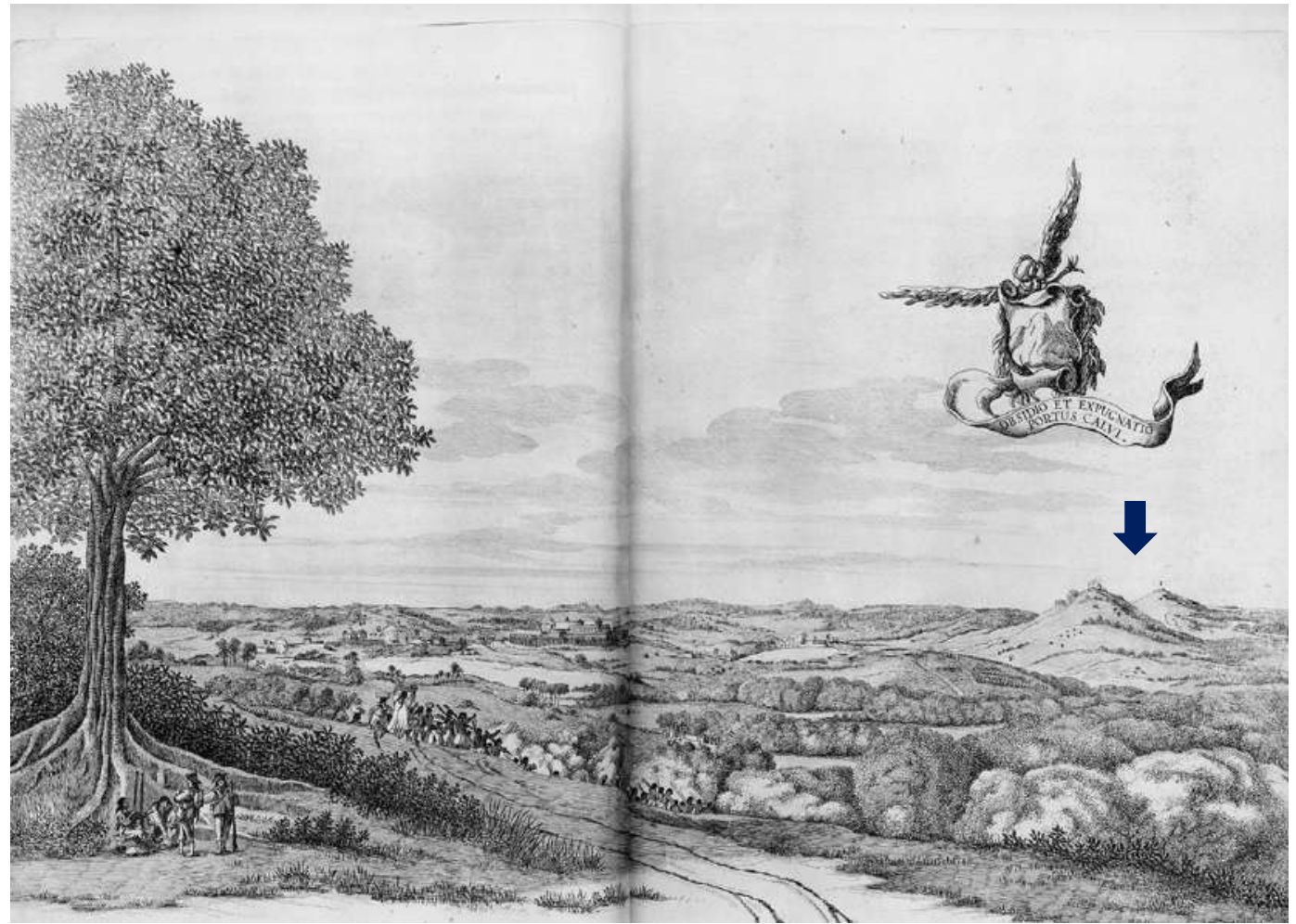

Figura 8: Obsidio et Expurgatio Portus Calvi Post, Frans Jansz, 1612-1680(il.). (Modificado, assinalando o reduto)

Todavia os cortes-teste realizados mostraram que parte do acervo arqueológico ainda se encontra preservado in situ. Cumpre salientar que as estruturas referidas como flanqueando a estrada do Norte, implantadas no outeiro de Amador Alvares, podem ainda preservar seu contexto arqueológico. Ainda que em superfície atualmente não mais se encontre vestígios evidentes de sua forma, a análise de imagens históricas mostrou que ainda recentemente restavam vestígios de suas estruturas de defesa passiveis de visualização à superfície, tal como na estrutura de defesa localizada na ilhota fluvial em frente à Porto Calvo, o Fort Bass, recentemente resgatado e restaurado (Figura 9).

No caso de um dos redutos que flanqueavam a estrada, restaram até pouco tempo, apenas as cicatrizes no terreno, como se pode observar na imagem histórico da Google Earth (Figura 10).

$\mathrm{Na}$ busca por eventuais vestígios relacionados às antigas ocupações históricas foi particularmente útil a avaliação topográfica das áreas, considerada não apenas em termos do relevo, mas ainda das áreas inundáveis, sobretudo no período do ano em que ocorreram as ações batavas (Figura 11). 


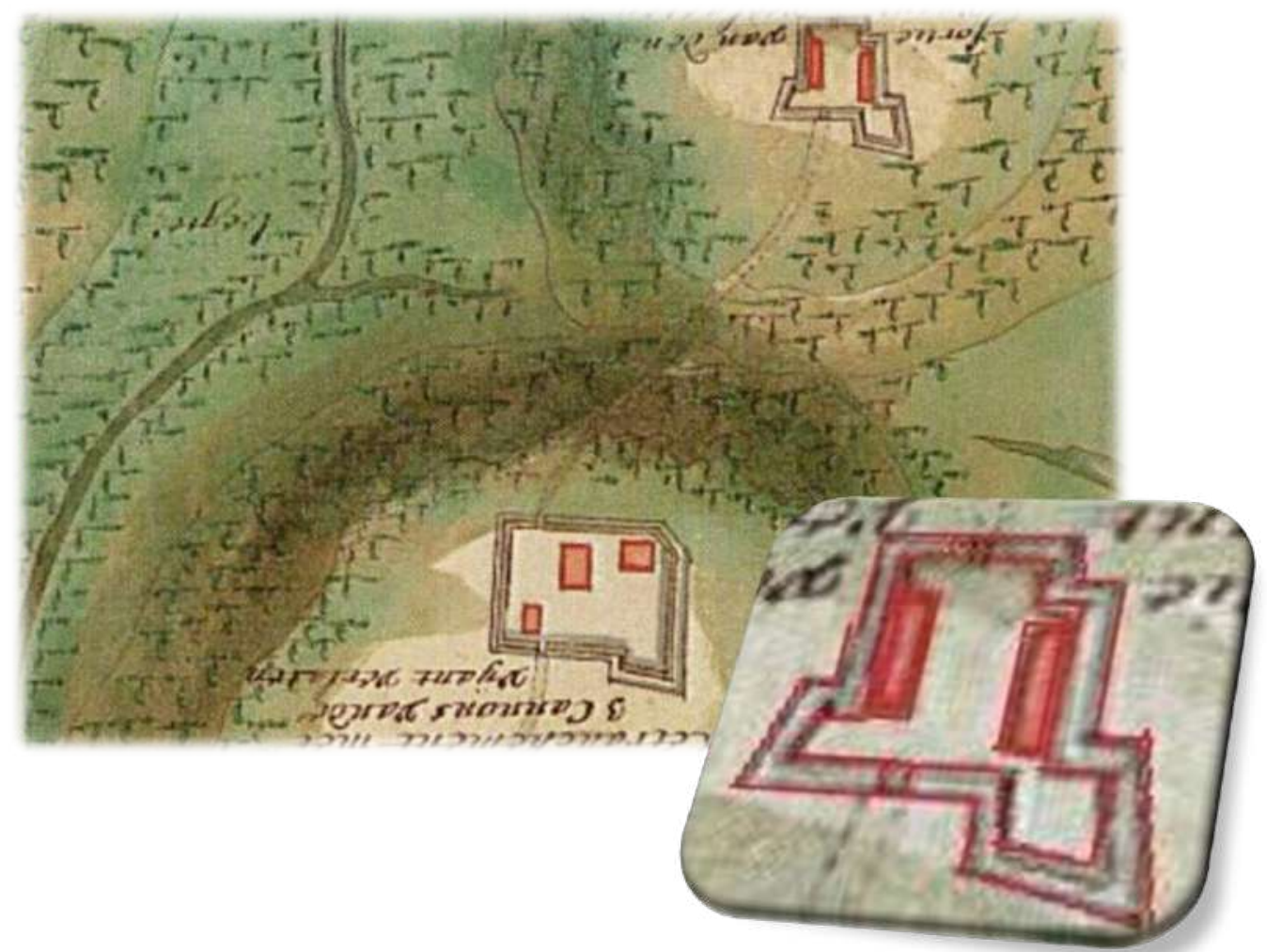

Figura 9: Redutos que flanqueavam a estrada. Detalhe do Christina Atlas/Vatican Atlas - BAV Reg.Lat. 2106-54 (sign. 65).
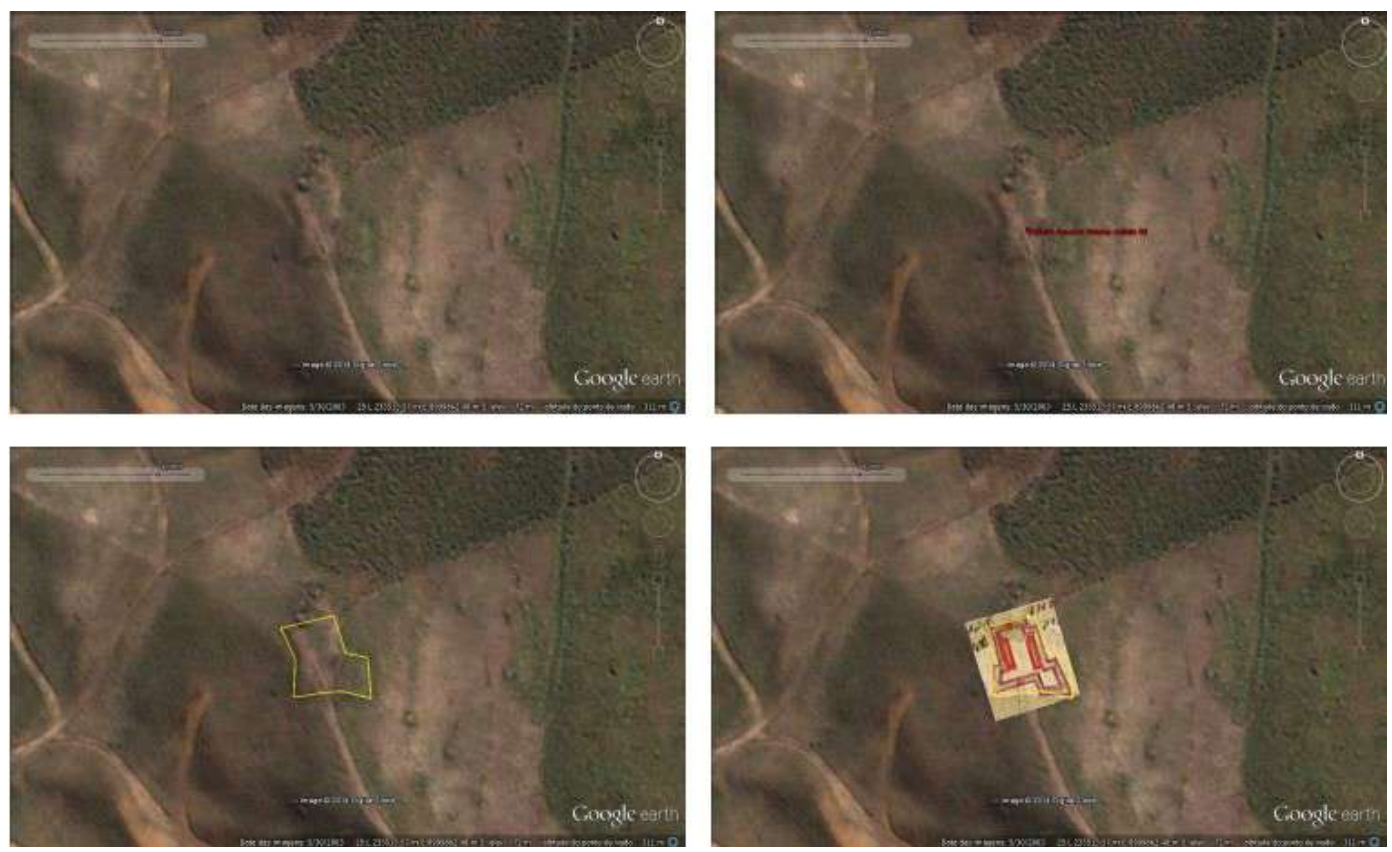

Figura 10: Imagem histórica do Google Earth que mostra claramente a cicatriz no terreno deixada provavelmente pela antiga estrutura fortificada. Observe-se a semelhança da cicatriz do terreno com a planta da fortificação que consta no Atlas de Johannes Vingboons. 


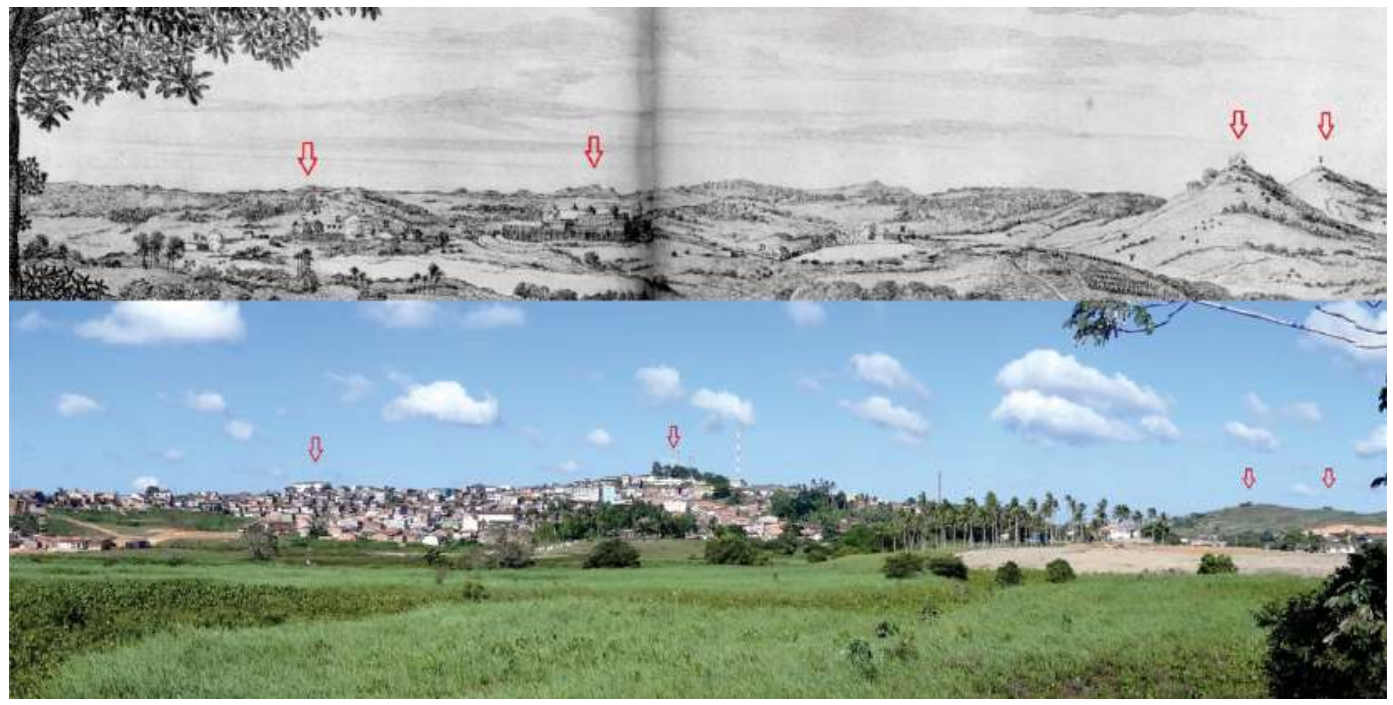

Figura 11: Porto Calvo vista do lado da margem esquerda do Rio Comandatuba. Pontos de referência assinalados (da esquerda para a direita): a Igreja nova; o forte do Bonsucesso, construído no entorno da igreja velha (hoje o hospital da cidade), um dos redutos que flanqueavam o caminho do Norte.

Os locais reconhecidos como de potencial arqueológico, mormente em áreas rurais, quando possível (permitido pelos proprietários) foram prospectados em superfície e em subsuperfície (cortes teste e trincheiras), e os resultados avaliados em termos de seu potencial como sítio arqueológico.

Nas áreas urbanas foram particularmente remarcáveis as informações obtidas sobre achados fortuitos, seja durante a execução de obras, seja em decorrência de desabamentos naturais. Tais informações foram mapeadas, e foram assinaladas no relatório da pesquisa.

Os resultados obtidos (positivos e negativos) foram graficamente assinalados sobre mapas da área, bem como todos os pontos em que a tradição oral aponta como locais em que teria havido achados fortuitos de material arqueológico, foram registrados, assinalando-se suas características em termos de tamanho aproximado (distribuição horizontal e vertical) e o período de ocupação ${ }^{8}$.

Nos locais em que foram observadas possíveis ocorrências de vestígios arqueológicos, fez-se o georeferenciamento, e incorporação à planta.

Com base no potencial arqueológico da área, estabelecido a partir dos dados secundários e da prospeç̧ão em campo, se fez a caracterização e avaliação da situação atual do patrimônio 
arqueológico da área de estudo - Diagnóstico - sugerindo tanto as ocorrências, como ainda sítios, que deverão ser alvo de estudo em detalhe.

Este talvez tenha sido um dos primeiros estudos, realizado no Brasil, com a adoção da metodologia utilizada. Não apenas com a metodologia, mas sobretudo com os resultados obtidos. Algo semelhante, mas com uma dimensão mais reduzida, já havia sido utilizado por nossa equipe na localização do Forte Mauricio, em Penedo, no estado de Alagoas, como foi mencionado, e ainda na localização do reduto da Restinga, no estado da Paraíba. Neste projeto o trabalho de campo, desenvolvido com uma grande retaguarda de gabinete, apresentou resultados que devem ser replicados em outras áreas antes que o avanço imobiliário destrua definitivamente páginas importantes da História brasileira.

Ao se elaborar o projeto, como ainda durante toda a sua execução, houve um exaustivo levantamento dos dados históricos, tanto textuais como iconográficos, primários e secundários que permitiu uma sincronia com os trabalhos que foram executados em campo. Constatou se a existência de uma grande complexidade relacionada com a ocupação holandesa no Estado de Alagoas, notadamente na documentação trabalhada, ao mesmo tempo em que também foi constatada a quase inexistência da materialidade desta ocupação. Esta constatação estimulou a nossa equipe, a cada dia da execução do projeto, a ir mais longe, a procurar vestígios desta ocupação, a pisar nos caminhos outrora utilizados pelas tropas, tanto holandesas como luso brasileiras, a entender todos estes espaços que tendem a desaparecer fisicamente, como já desapareceram de boa parte da memória alagoana e brasileira.

A prospeç̧ão de campo mostrou ainda a extensão do passivo em relação àquelas áreas consideradas de potencial arqueológico. Antigas edificações mal ou pouco conservadas até recentemente, têm sido irremediavelmente destruídas, cedendo espaço a novas formas de exploração do terreno, antes que qualquer estudo o tenha registrado. Mais recentemente o entorno de Porto Calvo tem sido alvo de profundas modificações em termos de uso do solo. Vastas extensões têm sido terraplanadas, com cortes e aterros, alterando as áreas alagáveis. Inclusive, uma destas áreas que estão sendo terraplanadas corresponde àquela onde teria ocorrido a batalha de Comandatuba. Novas estradas, novos loteamentos surgem no entorno da cidade, área que foi palco das manobras holandesas que culminaram com a tomada da então Vila. E os velhos redutos que deram apoio à defesa da Vila, muitos arrasados logo após os combates, restaram como cicatrizes no terreno, que pouco a pouco vão sendo inadvertidamente destruídos, talvez por não serem identificados, por não serem reconhecidos. 
A prospecção arqueológica trazendo à tona sua localização, seus contornos, representa um primeiro passo para seu resgate, para o resgate da memória alagoana dos tempos em que os flamengos buscaram se estabelecer nesta terra.

Como resultado pragmático deste trabalho temos hoje, não apenas um traçado de um caminho desenhado por um holandês no século XVII, mas a sua materialidade, que pode ser percorrido. O mesmo ocorrendo com a localização de engenhos, igrejas, habitações, portos, locais de batalha e fortificações.

O aproveitamento dos resultados desta pesquisa não apenas se constitui em obrigação do Estado, no tocante a sua preservação, como pode ser utilizado por outros segmentos da sociedade como o turismo cultural.

Os caminhos identificados podem ter balizas indicadoras. Residências, locais de igrejas, de engenhos, de portos, de fortificações e campos de batalha podem ter totens descritivos. 0 reduto da llha do Guedes, única estrutura fortificada preservada morfologicamente no Estado de Alagoas, identificada por nossa equipe, necessita de uma ação imediata por parte do IPHAN/AL e de outros órgãos de semelhante vocação para garantir a sua sobrevivência. Enfim, este projeto de pesquisa materializou parte de um grande potencial do Estado de Alagoas no tocante a ocupação holandesa do nordeste do Brasil. A preservação deste potencial de informações não cabe apenas ao IPHAN, mas a toda a sociedade alagoana e brasileira. A nossa equipe se sente particularmente honrada em ter contribuído para um melhor conhecimento desta região e deste período, pois acreditamos que uma sociedade que não conhece seu passado, não tem perspectiva de futuro.

\section{Referências}

albuquerque, M. A. G. M.; Albuquerque, V. C. L; NOGUeIRA, R. 2008. Levantamento HistóricoArqueológico da zona urbana de Porto de Pedras/AL. Recife: Laboratório de Arqueologia da UFPE.

AlbuQUerque, M. A. G. M.; ALBUQUerQUe, V. C. L; WALMSLEY, Doris L. 2014. Pesquisa arqueológica sobre a ocupação holandesa na bacia do rio Manguaba, municípios de Porto de Pedras e Porto Calvo, Estado de Alagoas. Relatório Final. Arqueolog Pesquisas, Camaragibe.

Albuquerque, M. A. G. M.; Albuquerque, V. C. L.; SilvA, M. A. da. 2005. Reconhecimento arqueológico em Penedo: estudo comparativo e georreferenciamento com base na iconografia histórica e na análise geoarqueológica do sítio do forte Maurício. Relatório Final. Recife: Laboratório de Arqueologia da UFPE.

ALLEN, S. J. Rota da Escravidão/Rota da Liberdade: etapa 1. (Relatório não acessado) 
BARLÉU, G. 1940. História dos feitos recentemente praticados durante oito anos no Brasil. Tradução e anotações de Cláudio Brandão, Ministério da Educação, Rio de Janeiro, Brasil, MCMXL.- versão em português, edição brasileira de 1940 acima referenciada, disponível em

http://www.brasiliana.usp.br/bbd/bitstream/handle/1918/03973800/039738_COMPLETO.pdf acesso em 10/9/2013.- edição original de 1647, em latim, disponível em

http://www.brasiliana.usp.br/bbd/bitstream/handle/1918/00246000/002460_COMPLETO.pdf acesso em 10/9/2013.

BLAEU, J. 2010. Atlas Maior Of 1665. [introduction and texts by Peter Van Der Krogt, based in the copy of Österreichische Nationalbibliothek, Vienna, with a selection of original texts by Joan Blaeu, directed and produced byBenedikt Taschen]. Taschen $\mathrm{GmbH}$, Köln, Deutschland. ISBN 978-3-8365-2412-4.

MARGGRAPHIUS, G. Brasilia qua parte paret Belgis. In: Klencke Atlas, mapa no 38. Kees Dierkz et filius D. K. compegerunt anno 1660. British Library, Londres, Inglaterra.

MENEZES, C. A. 2011. Alagoas de Marcgraf. 1옹 Simpósio Brasileiro de Cartografia Histórica, Paraty, maio de 2011. P 8.

PEREIRA, L. Brasilia Qua Parte Paret Belgis, disponível em: http://lhs.unb.br/wiki_files/HISTORIA.exe, Acesso em: 22 de junho de 2014

VISTA DO CERCO E CONQUISTA DE PORTO CALVO, detalhe do folheto Auctentijck Verhael van de Belegheringhe ende veroveringhe van Porto Calvo [Descrição autêntica do Cerco e Conquista de Porto Calvo], desenho atribuído ao Coronel Cristofel Arciszewsky e impresso por lan van Hilten, Amsterdam, 27/6/1637 (acervo do Nederlands Scheepvaartmuseum, Amsterdam). 